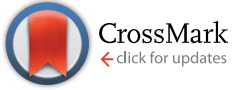

Cite this: J. Mater. Chem. A, 2014, 2, 13075

Received 15th April 2014

Accepted 17th June 2014

DOI: $10.1039 / \mathrm{c} 4 \mathrm{ta0} 01842 \mathrm{~g}$

www.rsc.org/MaterialsA

\section{Versatile control over size and spacing of small mesopores in metal oxide films and catalytic coatings via templating with hyperbranched core-multishell polymers $\uparrow$}

\author{
Denis Bernsmeier, ${ }^{a}$ Erik Ortel, ${ }^{a}$ Jörg Polte, ${ }^{b}$ Björn Eckhardt, ${ }^{a}$ Sabrina Nowag, ${ }^{c}$ \\ Rainer Haag ${ }^{\complement}$ and Ralph Kraehnert ${ }^{\star a}$
}

Controlling the pore structure of metal oxide films and supported catalysts is an essential requirement for tuning their functionality and long-term stability. Typical synthesis concepts such as "Evaporation Induced Self Assembly" rely on micelle formation and self assembly. These processes are dynamic in nature and therefore strongly influenced by even slight variations in the synthesis conditions. Moreover, the synthesis of very small mesopores $(2-5 \mathrm{~nm})$ and independent control over the thickness of pore walls are very difficult to realize with micelle-based approaches. In this contribution, we present a novel approach for the synthesis of mesoporous metal oxide films and catalytic coatings with ordered porosity that decouples template formation and film deposition by use of hyperbranched core-multishell polymers as templates. The approach enables independent control of pore size, wall thickness and the content of catalytically active metal particles. Moreover, dual templating with a combination of hyperbranched core-multishell polymers and micelles provides facile access to hierarchical bimodal porosity. The developed approach is illustrated by synthesizing one of the most common metal oxides $\left(\mathrm{TiO}_{2}\right)$ and a typical supported catalyst $\left(\mathrm{PdNP} / \mathrm{TiO}_{2}\right)$. Superior catalyst performance is shown for the gas-phase hydrogenation of butadiene. The concept provides a versatile and general platform for the rational optimization of catalysts based e.g. on computational prediction of optimal pore structures and catalyst compositions.

\section{Introduction}

Many applications in e.g. photovoltaics, ${ }^{\mathbf{1 , 2}}$ catalysis $^{\mathbf{3 , 4}}$ and photocatalysis $^{5,6}$ rely on mesoporous oxide coatings with tailored properties. In particular fast catalytic reactions require optimized pore systems that facilitate fast diffusion and high surface areas. Controlling the size and the shape of mesopores as well as the crystallinity and wall-thickness of the framework in such films are key factors for tuning their functionality and stability. ${ }^{7,8}$

Several strategies for improved control over the nanostructure of metal oxide coatings and supported catalysts have been reported. ${ }^{\mathbf{8} 9}$ So-called nanocasting provides access to tunable pore morphologies by replicating the nanostructure of a

${ }^{a}$ Department of Chemistry, Technische Universität Berlin, Straße des 17. Juni 124, 10623 Berlin, Germany. E-mail: ralph.kraehnert@tu-berlin.de

${ }^{b}$ Department of Chemistry, Humboldt-Universität zu Berlin, Brook-Taylor-Str. 2, 12489 Berlin, Germany

${ }^{c}$ Department of Chemistry, Freie Universität Berlin, Takustr. 3, 14195 Berlin, Germany $\dagger$ Dedicated to the occasion of the 80th birthday of Prof. Dr. Manfred Baerns

\$ Electronic supplementary information (ESI) available. See DOI: $10.1039 / \mathrm{c} 4 \mathrm{ta} 01842 \mathrm{~g}$ template material into an ordered pore system. ${ }^{\mathbf{1 0}}$ Oxide coatings with ordered and well-connected mesopores can be formed by a strategy called evaporation-induced self assembly (EISA). ${ }^{11-13}$

Typical EISA-based syntheses employ micelles of amphiphilic block-copolymers as pore templates and a reactive metal precursor dissolved in volatile solvent(s). The volatile solvent evaporates during film deposition leading to increasing polymer concentration, assembly of the template molecules into micelles and finally formation of an ordered mesophase comprised of micelles and condensed precursor. Subsequent thermal treatments induce stiffening of the inorganic network, crystallization and removal of the template. ${ }^{9}$

EISA is a dynamic and delicate process. Due to the transient nature of solvent evaporation and polymer self-assembly it reacts very sensitive to the synthesis conditions and the thermodynamics of the employed block-copolymers. Mesoporous $\mathrm{TiO}_{2}$ films based on e.g. the template Pluronic P123 were reported to form either lamellar, hexagonal or cubic phases ${ }^{\mathbf{1 4}}$ depending on the polymer concentration, $\mathrm{pH}$, temperature as well as on relative humidity applied during and after film deposition. $^{7}$ 
The strong sensitivity of EISA results in severe limitations of this synthesis approach. In the preparation of larger samples or thicker coatings local gradients in the evaporation conditions lead to inhomogeneities across the formed materials. Attempts to control pore size and wall thickness independently fail due to close interactions between template and precursor during self assembly. ${ }^{15}$ Moreover, the dynamic nature of micelles formed from amphiphilic block-copolymers typically makes the formation of well-ordered pore systems with small mesopores difficult to realize (see e.g. ref. 7 and 16 for $\mathrm{TiO}_{2}$ ).

Hyperbranched core-shell and core-multishell ("CMS") polymers offer a potential solution. They typically consist of a core (e.g. hyperbranched glycerol) and one or more shells of a different polymer (e.g. an alkyl layer and outer poly(ethylene glycol) layer). Core-multishell polymers that feature a hydrophobic core or inner shell and a hydrophilic outer shell resemble somehow the structure of polymer micelles typically employed for EISA. However, the nature of the polymer bonds is covalent, hence no polymer assembly into micelles is needed anymore.

Mesoporous powders of different metal oxides have been synthesized using CMS polymers as unimolecular pore templates. Yin et al. obtained a 2D mesoporous titania network employing amphiphilic core-double-shell polymers. ${ }^{17}$ Nowag et al. reported the synthesis of bimodal mesoporous $\mathrm{Pt} / \mathrm{SiO}_{2}$ powders using a mixture of a CMS polymer and micelles of a PEO-PPO-PEO (Pluronic P123). ${ }^{18}$ However, the obtained silica showed separated domains of unordered CMS-templated pores $\left(d_{\text {pore }} c a .2 \mathrm{~nm}\right)$ and larger SBA-15-type mesopores $\left(d_{\text {pore }} c a\right.$. $6 \mathrm{~nm}$ ) cast by P123 micelles. The studied CMS polymer also stabilized the colloidal Pt nanoparticles employed in the synthesis, ${ }^{18,19}$ demonstrating bifunctionality as pore template as well as particle stabilizer. However, the potential of CMS polymers to generate oxide coatings and catalysts with small mesopores, ordered porosity, materials with tunable pore-wall thickness and hierarchical porosity via dual templating remains so far unexplored.

We present a new strategy for polymer-templated metal oxide films with small mesopores and tunable wall thickness. The strategy gives direct access to hierarchical pore systems as well as catalytic functionality. The synthesis combines the advantages of EISA and CMS polymer templates. CMS polymers, consisting of hyperbranched polyglycerol cores, hydrophobic inner alkyl layers and a hydrophilic outer layer of monomethylated poly(ethylene glycol), are shown to control the obtained pore size and to act as particle stabilizers. This novel approach enables for the first time (i) the synthesis of nanocrystalline metal oxide films with ordered pores and size control between 3 and $5 \mathrm{~nm}$, (ii) independent control over the thickness of pore walls and the size of the mesopore by adjusting the content of CMS polymer in the dip-coating solution, (iii) metal oxide films with hierarchical bimodal mesoporosity obtained by combining CMS polymers with micelle-based templates, and (iv) catalytic coatings $\mathrm{PdNP} / \mathrm{TiO}_{2}$ with small mesopores. The obtained catalysts show the highest activity reported so far in literature for selective gas-phase hydrogenation of 1,3butadiene.

\section{Experimental}

\section{Chemicals and materials}

$\mathrm{Na}_{2} \mathrm{PdCl}_{4} \cdot 3 \mathrm{H}_{2} \mathrm{O}(99.95 \%)$ and $\mathrm{NaBH}_{4}(98 \%)$ were obtained from Alfa Aesar and $\mathrm{TiCl}_{4}$ (99.9\%) from Acros. Ethanol (99.9\%) was purchased from Roth. These chemicals were used without further purification. Water was purified $(18.2 \mathrm{M} \Omega \mathrm{cm}$ MilliQ, Millipore). Si wafers and steel plates (grade 1.4301) were employed as substrates for film deposition. Before dip-coating, $\mathrm{Si}$ wafers were cleaned with ethanol. The surface of steel plates was grinded with 180-grit sandpaper and thoroughly cleaned as described in earlier publications. ${ }^{4,20}$ Prior to coating, Si wafers and steel plates were calcined in air for $2 \mathrm{~h}$ at $600{ }^{\circ} \mathrm{C}$.

Two different polymers with core-multishell structure, called CMS5 and CMS10 hereafter, were employed as templates. CMS5 consisted of a hyperbranched polyglycerol core with a molar mass of approximately $5000 \mathrm{~g} \mathrm{~mol}^{-1}$, an intermediate shell of $\mathrm{C}_{18}$ alkyl chains and an outer shell of monomethylated poly(ethylene glycol) $\left(\mathrm{mPEG}_{750}\right)$ with a total mass of the polymer of $M_{\mathrm{w}}=93300 \mathrm{~g} \mathrm{~mol}^{-1} \cdot{ }^{18} \mathrm{CMS} 10$ consisted of a hyperbranched polyglycerol core with a molar mass of approximately $10000 \mathrm{~g} \mathrm{~mol}^{-1}$, an intermediate shell of $\mathrm{C}_{12}$ alkyl chains and an outer shell of monomethylated poly(ethylene glycol) $\left(\mathrm{mPEG}_{750}\right.$, $M_{\mathrm{w}}=750 \mathrm{~g} \mathrm{~mol}^{-1}$ ) with a total mass of $M_{\mathrm{w}}=56500 \mathrm{~g} \mathrm{~mol}^{-1}$. The synthesis of the CMS polymers was realized by amide coupling of the shell molecules to the hyperbranched core as described by Keilitz et al. ${ }^{21}$ Amphiphilic block copolymers poly(ethylene oxide)- $b$-poly(butadiene)- $b$-poly(ethylene oxide) (PEO-PB-PEO containing $18700 \mathrm{~g} \mathrm{~mol}^{-1}$ PEO and $10000 \mathrm{~g}$ $\left.\mathrm{mol}^{-1} \mathrm{~PB}\right)$ were obtained from Polymer Service Merseburg $\mathrm{GmbH}$ (see ref. 15 for details).

\section{Mesoporous $\mathrm{TiO}_{2}$ coatings}

For the synthesis of mesoporous $\mathrm{TiO}_{2}$ films, CMS5, CMS10 or micelles formed from PEO-PB-PEO were used as pore template and $\mathrm{TiCl}_{4}$ as precursor in an ethanolic solution. The amount of CMS polymers was varied between $12 \mathrm{mg}$ and $174 \mathrm{mg}$. The amount of employed PEO-PB-PEO was $75 \mathrm{mg}$. The polymer was dissolved in $3.68 \mathrm{ml}$ of ethanol and $333 \mu \mathrm{l}$ of water and stirred for $12 \mathrm{~h}$. Thereafter $2.32 \mathrm{ml}$ of a homogeneous mixture of $\mathrm{TiCl}_{4}$ (908 $\mathrm{mM})$ and ethanol were added at room temperature. The obtained mixture was stirred for $1 \mathrm{~h}$.

Dip-coating of all samples was performed with a withdrawal rate of $300 \mathrm{~mm} \mathrm{~min}^{-1}$ in a controlled atmosphere of $\mathrm{RH}=40 \%$ at $25^{\circ} \mathrm{C}$. The films were subsequently dried at $80^{\circ} \mathrm{C}$ for $4 \mathrm{~h}$ in a tube furnace under flowing air. To remove the templates the temperature was then raised in flowing air with $1 \mathrm{~K} \mathrm{~min}^{-1}$ to $300{ }^{\circ} \mathrm{C}$, held constant for $1 \mathrm{~h}$ and followed by naturally cooling down to room temperature. To further crystallize the $\mathrm{TiO}_{2}$ framework, the obtained films were treated with a second calcination procedure ramping with $3 \mathrm{~K} \mathrm{~min}^{-1}$ to $450{ }^{\circ} \mathrm{C}$ and holding this temperature for $5 \mathrm{~min}$ followed by cooling to room temperature.

\section{$\mathrm{PdNP} / \mathrm{TiO}_{2}$ catalyst}

Colloidal Pd nanoparticles were prepared by reduction of $\mathrm{Na}_{2} \mathrm{PdCl}_{4}$ in an ethanolic solution with CMS10 acting as 
stabilizer and $\mathrm{NaBH}_{4}$ as reducing agent. The required amount of $\mathrm{Na}_{2} \mathrm{PdCl}_{4}$ was first dissolved in ethanol $(11 \mathrm{mM})$. Then $3.68 \mathrm{ml}$ of this solution were mixed with $70 \mathrm{mg}$ of CMS10 and stirred for $12 \mathrm{~h}$ at room temperature. Thereafter $333 \mu \mathrm{l}$ of a freshly prepared aqueous solution of $\mathrm{NaBH}_{4}(366 \mathrm{mM})$ were quickly added to form a colloid with a dark brownish color. The $\mathrm{PdNP} / \mathrm{TiO}_{2}$ catalysts were synthesized by adding to the CMS10stabilized PdNP colloid $2.32 \mathrm{ml}$ of a homogeneous mixture of $\mathrm{TiCl}_{4}(908 \mathrm{mM})$ and ethanol. Dip-coating and thermal treatments were performed as already described for the $\mathrm{TiO}_{2}$ film synthesis. After calcination at $450{ }^{\circ} \mathrm{C}$ the catalysts were reduced for $6 \mathrm{~h}$ at $350{ }^{\circ} \mathrm{C}$ in $\mathrm{H}_{2} / \mathrm{Ar}$ atmosphere $\left(4 \mathrm{vol} \% \mathrm{H}_{2}\right)$.

\section{Characterization}

SEM images were collected with a JEOL $7401 \mathrm{~F}$ scanning electron microscope. To determine the film thickness, coated samples were split into two pieces and imaged at the cross-section. Image J Version 1.45s (http://rsbweb.nih.gov/ij) was employed to determine pore diameter, film thickness and PdNP particle diameter and to derive FFT plots from the SEM images. Size and crystallinity of colloidal nanoparticles as well as film morphology and crystallinity of film fragments were studied by TEM (FEI Tecnai G2 20 S-TWIN instrument operated at $200 \mathrm{kV}$ ).

Lab scale SAXS analysis of dissolved CMS polymers in ethanol was performed using a SAXSess instrument (Anton Paar $\mathrm{GmbH}$ ). Obtained scattering curves were analyzed with the assumptions of spherical shape, homogeneous electron density and a Schulz-Zimm size distribution.

2D-SAXS pattern with a beam incident angle of $\beta=13^{\circ}$ or $90^{\circ}$ in respect to the film surface were recorded at the HASYLAB B1 beamline at DESY Hamburg with a sample to detector distance of $1338 \mathrm{~mm}$ and a calibrated radiation energy of $16026 \mathrm{eV}$ using a $2 \mathrm{D}$ PILATUS $1 \mathrm{M}$ detector. The SAXS data were processed employing the software FIT2D Version V12.077. The modulus of the scattering vector $q$ is defined in terms of the scattering angle $\theta$ and the wavelength $\lambda$ of the radiation used: thus $q=4 \pi /$ $\lambda \sin (\theta / 2)$. XRD was measured on a Bruker D8 Advance ( $\mathrm{Cu} \mathrm{K} \alpha$ radiation) with gracing incident beam $\left(1^{\circ}\right)$. Reflexes were assigned using PDFMaintEx library Version 9.0.133. The average crystallite size was calculated applying the Scherrer equation. Obtained data were analyzed with the Rietveld method using TOPAS V4.2 (Bruker AXS). Experimental settings were considered by the Fundamental Parameter approach incorporated in the program. Phases of anatase (I41/amd) and palladium $(\mathrm{Fm} 3 \mathrm{~m})$ were refined using scale factor, lattice parameter and crystallite size. Influence of four background parameters and zero point error were taken into account. The crystallite sizes were calculated from peak broadening based on the volume-weighted column height.

The Pd concentration was determined using inductively coupled plasma-optical emission spectroscopy (ICP-OES) using a 715-ES-inductively coupled plasma (ICP) analysis system (Varian).

$\mathrm{Kr}$ adsorption was measured at $77 \mathrm{~K}$ using the Autosorb-1-C automated gas adsorption station from Quantachrome. The surface area was calculated via Brunauer-Emmett-Teller (BET) method. Before adsorption measurement the samples were degassed at $150{ }^{\circ} \mathrm{C}$ for $2 \mathrm{~h}$ in vacuum. To determine the coating mass, the mass depth of each film was calculated by STRATAGem film analysis software ( $\mathrm{v} 4.3$ ) based on WDX spectrums analyzed with the Cameca "Camebax-microbeam" electron microprobe at ZELMI (TU-Berlin). In this study, BET surface area values are related either to the coating mass $\left(\mathrm{m}^{2} \mathrm{~g}^{-1}\right)$ or to the geometric film volume $\left(\mathrm{m}^{2} \mathrm{~cm}^{-3}\right)$.

\section{Catalytic testing}

The catalytic performance of $\mathrm{PdNP} / \mathrm{TiO}_{2}$ catalyst films in the gas-phase hydrogenation of 1,3-butadiene was studied at temperatures between 50 and $150^{\circ} \mathrm{C}$. Films were coated on both sides of steel plates (plate size $27 \mathrm{~mm} \times 30 \mathrm{~mm}$ ). Five identical steel plates were stacked parallel into the reactor housing with $1.5 \mathrm{~mm}$ distance between the plates. The total coating mass amounted to $2.3 \mathrm{mg}$. A test setup and procedure similar to the one described in ref. 4 and 22 was used. A reaction mixture consisting of $10 \%$ butadiene (2.5 purity), 20\% hydrogen (5.0 purity), and 70\% nitrogen (5.0 purity) was passed through

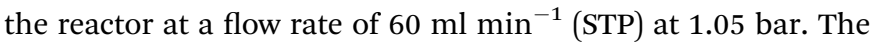
catalyst was then heated to $150{ }^{\circ} \mathrm{C}$ under reactive gas flow and equilibrated to reaction conditions for $4 \mathrm{~h}$. Thereafter, the temperature was decreased stepwise in $10 \mathrm{~K}$ increments to $50{ }^{\circ} \mathrm{C}$ with a dwell time of $3 \mathrm{~h}$ for each temperature set point. Analysis of the gas products was performed continuously every 7 min by online gas chromatography (Agilent GC 7890 equipped with FID, TCD and columns HP Plot $\mathrm{Al}_{2} \mathrm{O}_{3}$, Molsieve 5A, HP Plot Q and DB FFAP.) The space-time yield (STY) was calculated as produced moles of butenes per second per kilogram of the catalyst $\left[\mathrm{mol} \mathrm{s}^{-1} \mathrm{~kg}^{-1}\right]$.

\section{Results and discussion}

The following sections describe first the physico-chemical properties of dissolved CMS polymers and of mesoporous $\mathrm{TiO}_{2}$ films templated with CMS polymers. Thereafter, control over the thickness of pore walls is demonstrated. Moreover, the generation of hierarchical porosity by dual templating with CMS polymers and micelles of PEO-PB-PEO is reported. Finally, a mesoporous $\mathrm{PdNP} / \mathrm{TiO}_{2}$ catalysts templated by CMS polymers is presented as well as its performance in butadiene hydrogenation.

\section{CMS polymers in solution}

To proof that CMS polymers can act as unimolecular mesopore templates, the size of CMS polymers dissolved in ethanol was analyzed by SAXS. SAXS scattering curves of CMS5 and CMS10 and the corresponding fits are shown in ESI Fig. S1.f Fitting the curves with a theoretical model indicates diameters of the polymer structures of $6.6 \mathrm{~nm}$ (CMS5) and $8.8 \mathrm{~nm}$ (CMS10) and about $30 \%$ polydispersity. Hence, both studied CMS polymers form individual dissolved entities with narrow size distribution and diameters smaller than the micelles of typical template polymers (see e.g. ref. 15). 


\section{Mesoporous $\mathrm{TiO}_{2}$ film templated with CMS10}

To proof the synthesis concept and understand the influence of calcination temperature titania films were deposited from solutions containing $\mathrm{CMS10}, \mathrm{TiCl}_{4}$, ethanol and water and calcined at 300 and $450{ }^{\circ} \mathrm{C}$, respectively. The resulting films have a thickness of circa $80 \mathrm{~nm}$. Fig. $1 \mathrm{~A}-\mathrm{C}$ and $\mathrm{G}$ presents analysis of the sample calcined at $300{ }^{\circ} \mathrm{C}$ by SEM, SAXS and XRD. The film surface features an abundance of pores with diameters of about 4 to $5 \mathrm{~nm}$ (Fig. 1A, SEM). The FFT image corresponding to the SEM micrograph (inset in Fig. 1A) shows a distinct ring corresponding to periodic distances of about $9 \mathrm{~nm}$. Hence, the film surface consists of locally ordered mesopores imprinted by the hyperbranched CMS polymer.

The 2D SAXS pattern recorded perpendicular to the substrates surface $\left(\beta=90^{\circ}\right.$, Fig. 1B) features an isotropic ring, which confirms the ordered pore structure. The corresponding $d$-spacing in $x$-direction $d_{x} \approx 8.4 \mathrm{~nm}\left(q_{x} \approx 0.75 \mathrm{~nm}^{-1}\right)$ corresponds well with the periodicity of $9 \mathrm{~nm}$ observed by SEM on the film surface. The pattern recorded at a smaller angle $\left(\beta=13^{\circ}\right.$, Fig. 1C) shows an ellipsoidal shape. Such patterns are typically attributed to an ordered mesostructure after isotropic shrinkage in the direction normal to the substrate. ${ }^{23,24} \mathrm{~A}$ comparison of $d_{x}$ with the $d$-spacing in $z$-direction $\left(q_{z} \approx\right.$ $1.93 \mathrm{~nm}^{-1} ; d_{z} \approx 3.3 \mathrm{~nm}$ ) suggests an anisotropic shrinkage of approximately 61\%. XRD analysis of the sample (Fig. 1G) does not show distinct reflections that could be assigned to a crystalline titania phase.

The observed film properties are consistent with data reported for mesoporous EISA-based $\mathrm{TiO}_{2}$ films synthesized from block-copolymer templates, except for the smaller pore size and $d$-spacing. Anisotropic shrinkage of about $60 \%$ was reported for $\mathrm{TiO}_{2}$ films templated by micelles of $\mathrm{F} 127,{ }^{24} \mathrm{ca}$. $70 \%$ for PEO-PB-PEO polymers. ${ }^{15}$ The circular $\left(\beta=90^{\circ}\right)$ and elliptical scattering features $\left(\beta=13^{\circ}\right)$ are similar to scattering
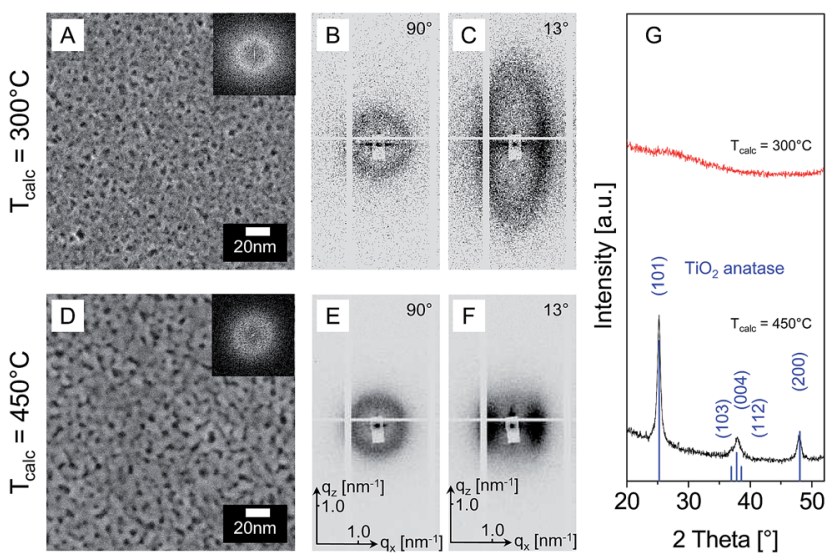

Fig. 1 SEM, SAXS and XRD analysis of CMS10-templated $\mathrm{TiO}_{2}$ films The top row shows results for films calcined at $300^{\circ} \mathrm{C}$, the bottom row films calcined at $450{ }^{\circ} \mathrm{C}$. (A and D) Top-view SEM images with FFT insets. 2D-SAXS pattern recorded in transmission mode with an incident angle of $\beta=90^{\circ}$ ( $\mathrm{B}$ and $\mathrm{E}$ ) and $13^{\circ}$ ( $\mathrm{C}$ and $\mathrm{F}$ ). (G) XRD pattern recorded in grazing incidence mode ( $1^{\circ}$ in respect to film surface). Assigned $(h k l)$ indices correspond to crystalline $\mathrm{TiO}_{2}$ anatase (PDF 211272). patterns previously assigned to a distorted cubic arrangement of micelle-templated mesopores. ${ }^{23}$ However, the pore ordering in films templated by CMS polymers appears to be less pronounced than reported for many titania films templated by micelles of e.g. F127, ${ }^{24} \mathrm{P} 123,{ }^{14}$ Brij 58. ${ }^{16,25}$ The lower degree of pore ordering could be related to the polydispersity of the employed CMS polymer which have a polydispersity index of approximately 1.5. Also the low crystallinity is typical for micelle-templated $\mathrm{TiO}_{2}$ films calcined at $300{ }^{\circ} \mathrm{C} .{ }^{26}$

\section{Impact of calcination temperature}

CMS10-templated films calcined at $300{ }^{\circ} \mathrm{C}$ were heated in air to $450{ }^{\circ} \mathrm{C}$ ( $3 \mathrm{~K} \mathrm{~min}^{-1}, 5 \mathrm{~min}$ dwell time) to induce further crystallisation. Fig. 1 presents corresponding SEM images (D), 2DSAXS patterns (E and F) and XRD data (G). SEM analysis of the film evidences pores with a diameter of about 4 to $5 \mathrm{~nm}$ (Fig. 1D), i.e. the same size as for the sample calcined at $300{ }^{\circ} \mathrm{C}$. However, pore walls appear to be more compact as for the $300{ }^{\circ} \mathrm{C}$ calcined film (Fig. 1A). The FFT image corresponding to the SEM data (inset in Fig. 1D) contains a distinct ring corresponding to a periodic distance of 9 to $10 \mathrm{~nm}$. 2D-SAXS recorded in transmission at $\beta=90^{\circ}$ features an isotropic ring (Fig. 1E). The SAXS pattern at $\beta=13^{\circ}$ (Fig. 1F) shows reflections in $x$ - and $z$-direction, but no full ellipsoidal shape. The pattern suggests a loss of pore periodicity in $z$-direction during calcination at $450{ }^{\circ} \mathrm{C}$, possibly resulting from pore degradation due to crystallite growth. XRD analysis of the $450{ }^{\circ} \mathrm{C}$ calcined sample (Fig. 1G) confirms the presence $\mathrm{TiO}_{2}$ anatase as indicated by the reflections at 2 theta angles of $25.28^{\circ}(101), 36.95^{\circ}(103), 37.80^{\circ}$ (004), 38.58 ${ }^{\circ}$ (112), 48.05 (200) [PDF 21-1272]. The average crystallite size determined by Rietveld refinement amounts to about $14 \mathrm{~nm}$. This observation agrees well with evidence derived from the microscopy and SAXS (Fig. 1D and F) that the pore systems order slightly degrades at $450{ }^{\circ} \mathrm{C} .{ }^{15,27}$

The surface area (Kr sorption) of the CMS10-templated films amounts to $182 \mathrm{~m}^{2} \mathrm{~g}^{-1}$ or $703 \mathrm{~m}^{2} \mathrm{~cm}^{-3}\left(T_{\text {calc }}=300{ }^{\circ} \mathrm{C}\right)$ and $59 \mathrm{~m}^{2} \mathrm{~g}^{-1}$ or $236 \mathrm{~m}^{2} \mathrm{~cm}^{-3}\left(T_{\text {calc }}=450{ }^{\circ} \mathrm{C}\right)$, respectively. In comparison, micelle-templated anatase films $\left(\mathrm{PEO}_{213}-\mathrm{PB}_{184}{ }^{-}\right.$ $\mathrm{PEO}_{213}, \mathrm{TiCl}_{4}$ ) calcined at $475{ }^{\circ} \mathrm{C}$ offer a surface area of $85 \mathrm{~m}^{2} \mathrm{~g}^{-1} .^{15} 113 \mathrm{~m}^{2} \mathrm{~g}^{-1}$ were reported by $\mathrm{Yu}$ et al. for $\mathrm{TiO}_{2}$ anatase films synthesized from titanium tetraisopropoxide/ Pluronic P123 after calcination at $400{ }^{\circ} \mathrm{C}^{28}$ Hence, the surface area of CMS10-templated $\mathrm{TiO}_{2}$ is in the same order of magnitude as observed for micelle-templated $\mathrm{TiO}_{2}$. The high surface area of the CMS-templated films implies that mesopores are interconnected and accessible to krypton gas.

The combined data confirms that hyperbranched coremultishell polymers can template ordered mesopores of about 4-5 nm size in $\mathrm{TiO}_{2}$ films. Pore sizes are smaller than typically obtained with micelles of amphiphilic block-copolymers. Additional tests on the influence of relative humidity during dip-coating (see ESI Fig. S2 ) prove that the synthesis is also more robust than typical EISA syntheses. In contrast to Pluronic-templated films, ${ }^{29}$ the pore morphology of CMS-templated $\mathrm{TiO}_{2}$ did not change for relative humidities between 12 and $80 \%$. 


\section{Controlling the thickness of pore walls}

The wall thickness of a porous material is a critical parameter for its thermal stability. Mesoporous titania films with different wall thicknesses were synthesized by changing the concentrations of the CMS10 polymer template in the dip-coating solution while keeping the amount of precursor constant. Fig. 2A-F shows top-view SEM and FFT images of the respective films after calcination at $300{ }^{\circ} \mathrm{C}$. Fig. $2 \mathrm{G}$ summarizes the influence of the mass ratio between CMS template and precursor on pore diameter and on the periodic distances between pores.

Increasing concentrations of the CMS10-template result in films with similar morphologies (Fig. 2A-F). The resulting film thicknesses range from $70 \mathrm{~nm}$ to $95 \mathrm{~nm}$. Templated mesopores with about $4 \mathrm{~nm}$ diameter can be observed for all concentrations. FFTs for all images indicate the preserved pore ordering. However, the pore spacing systematically changes as indicated by the changing diameter of the ring seen in the FFTs. The periodic spacing decreases monotonously from $10 \mathrm{~nm}$ to $6 \mathrm{~nm}$ with increasing polymer content, which indicates a decrease in the wall thickness of the templated pores. Hence, the developed synthesis enables for the first time for pore diameter smaller $5 \mathrm{~nm}$ the control of the pore-wall thickness independent of the templated mesopore size.

\section{Controlling pore size}

The control of pore size is particularly important for catalyst design. For micelle-templated films the obtained pore size can be controlled by the employed structure-directing agent. We therefore tested a second template polymer CMS5 in order to establish pore-size control in a similar fashion also for small mesopores. CMS5 features a significantly smaller hyperbranched core $\left(5000 \mathrm{~g} \mathrm{~mol}^{-1}\right)$ than CMS10 (10 $\left.000 \mathrm{~g} \mathrm{~mol}^{-1}\right)$.

Fig. 3 (left column, $1: 0$ ) displays SEM (a and b) and FFT (c) images of $\mathrm{a} \mathrm{TiO}_{2}$ film templated with CMS5 polymer. The films morphology strongly resembles that of CMS10 templated $\mathrm{TiO}_{2}$ (Fig. 1A) showing an abundance of locally ordered mesopores. However, pore diameter $(3 \mathrm{~nm})$ and periodic distance $(7.5 \mathrm{~nm})$

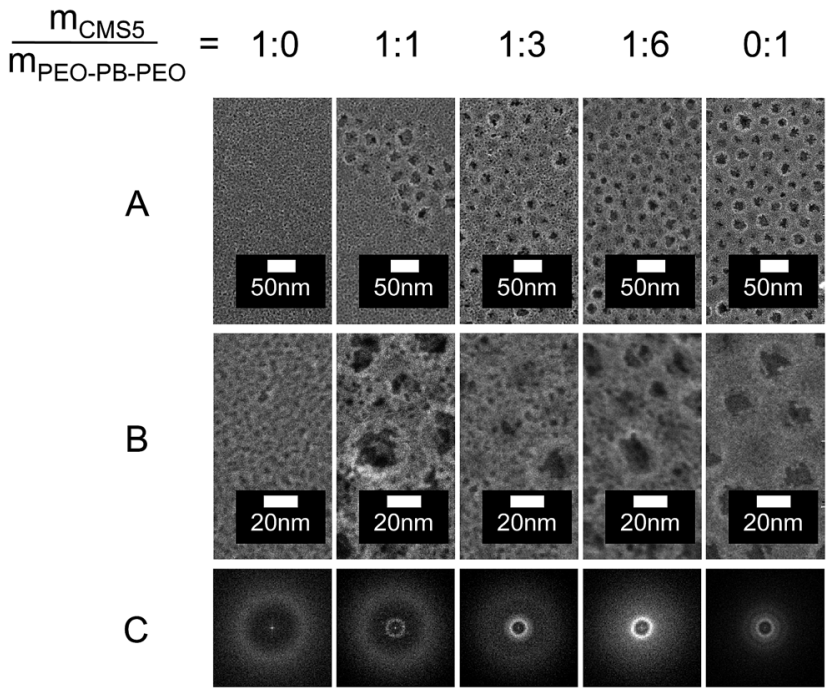

Fig. 3 Influence of the ratio between CMS5 and PEO-PB-PEO polymer in dual templating with two different porogens for $\mathrm{TiO}_{2}$ films calcined at $300{ }^{\circ} \mathrm{C}$. (A and B) SEM images, (C) FFT. The amount of PEO-PB-PEO increases from left ( $1: 0$, no micelles) to right $(0: 1$, no CMS5, pores from PEO-PB-PEO only). Mass ratios of $1: 1$ and $1: 3$ induce bimodal porosity with separate pore domains, at a ratio $1: 6$ all smaller mesopores are located inside the wall formed by larger mesopores.

are apparently smaller than for the films templated with CMS10 (4-5 $\mathrm{nm}$ and $9 \mathrm{~nm}$, respectively). The smaller structural features produced by CMS5 agree well with the observation that CMS5 forms also smaller polymer entities already in solution (SAXS: $6.6 \mathrm{~nm}$ ) than CMS10 (SAXS: $c a .8 .3 \mathrm{~nm}$, see ESI S1\%). Hence, the size of templated mesopores can be controlled by the size of the dissolved polymer template, which can be related to the molar weight of its hyperbranched core.

\section{Hierarchical porosity by dual templating with CMS5 and micelles of PEO-PB-PEO}

Hierarchical pore systems can show superior performance in applications that rely on fast mass transport such as catalysis.

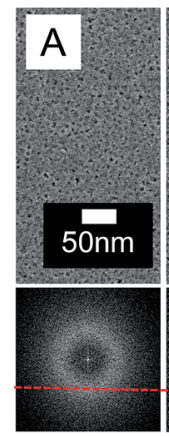

8.0

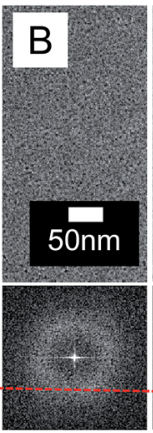

12.1

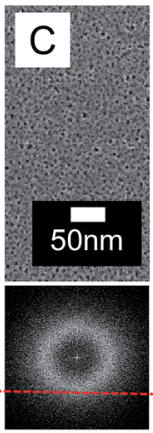

17.5

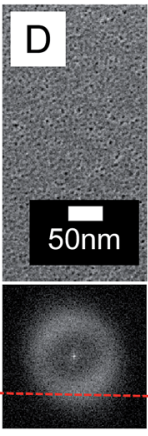

27.3

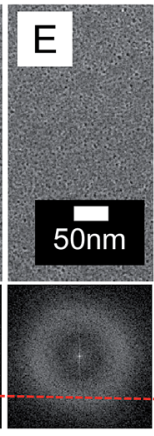

35.2

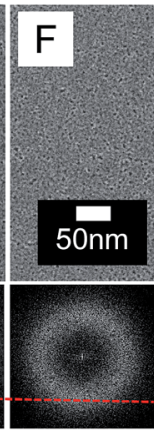

43.4

mass template per $100 \mathrm{mg} \mathrm{TiCl}_{4}[\mathrm{mg}]$

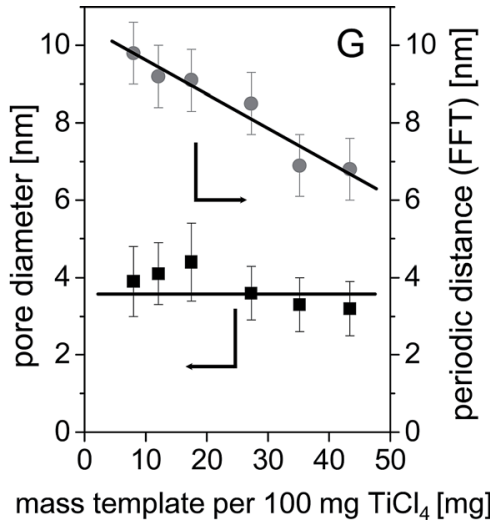

mass template per $100 \mathrm{mg} \mathrm{TiCl}_{4}[\mathrm{mg}]$

Fig. 2 Influence of the content of CMS10 polymer on pore size and pore spacing in $\mathrm{TiO}_{2}$ films calcined at $300{ }^{\circ} \mathrm{C}$. (A-F) SEM and FFT, (G) image evaluation. CMS10 content increases from left to right. Values are given as mass of template per $100 \mathrm{mg} \mathrm{TiCl}_{4}$ in the dip-coating solution. (G) Plots the measured pore diameter (SEM) and regular distances (from FFT) vs. the amount of template. Increasing polymer content decreases the spacing between pores while the pore size remains almost constant. 
The feasibility of synthesizing $\mathrm{TiO}_{2}$ films with hierarchically organized bimodal porosity was tested combining different amounts of the smaller core-multishell polymer CMS5 with micelles of $\mathrm{PEO}_{213}-\mathrm{PB}_{184}-\mathrm{PEO}_{213}$ block-copolymers in the same dip-coating solution.

Fig. 3 presents SEM images in low (A) and high (B) magnification and corresponding FFTs (C) of calcined titania films templated with either CMS5 ("1:0"), with different mixtures of CMS5 and PEO-PB-PEO (mass ratio $1: 1,1: 3,1: 6$ ), and with PEO-PB-PEO only ("0 : 1 "). The mass ratio between CMS5 and PEO-PB-PEO increases from left to right in Fig. 3. This was realized by varying the amount of CMS5 in the employed dipcoating solutions. The film thicknesses range from $70 \mathrm{~nm}$ to $100 \mathrm{~nm}$.

SEMs image of the film templated with CMS5 polymer (Fig. 3, 1:0) show mesopores on the outer film surface with a pore diameter of $c a .3 \mathrm{~nm}$. The periodic distance from FFT amounts to $7.5 \mathrm{~nm}$. Templating with micelles of PEO-PB-PEO in the absence of CMS templates produces $\mathrm{TiO}_{2}$ structures with large mesopores of about $20 \mathrm{~nm}$ diameter and a periodic distance of $29.3 \mathrm{~nm}$ (Fig. 3, ratio $0: 1$ ) (see ref. 15 for more details). For all films synthesized with the template mixtures (Fig. 3, 1:1, 1:3, 1:6) a bimodal porosity can be clearly recognized. All systems show mesopores with the desired pore diameters of about $3 \mathrm{~nm}$ originating from CMS5 and $20 \mathrm{~nm}$ from PEO-PB-EPO micelles, respectively. However, the films differ in the local distribution of the differently templated pores. At a mass ratio CMS5 to PEO-PB-PEO of $1: 1$ separated pore domains for each template are formed (Fig. 3, $1: 1$ ). FFT images show therefore two distinct rings with periodic distances of $7.0 \mathrm{~nm}$ and $28.0 \mathrm{~nm}$ corresponding to individual domains of the respective polymer template.

The size of the individual domains decreases with increasing PEO-PB-PEO content as indicated by SEM and FFT (Fig. 3, $1: 3)$. The individual domains of PEO-PB-PEO finally disappear at a ratio CMS5 to PEO-PB-PEO of $1: 6$. Large $20 \mathrm{~nm}$ pores are homogeneously distributed across the whole film, with smaller CMS5-templated pores located in all the walls of the larger mesopores (Fig. 3, 1:6). The respective FFT shows one clear ring which corresponds to the periodic distances of the PEOPB-PEO-templated pore structure and a broad halo originating from the smaller pore spacings. Hence, the combined data suggest that a hierarchically organized bimodal porosity is obtained.

It should be noted that also the available surface area changes significantly with the introduction of hierarchical porosity. The BET surface area of a CMS5-templated film amounts to $1050 \mathrm{~m}^{2} \mathrm{~cm}^{-3}$, whereas a film prepared with a CMS5 to PEO-PB-PEO ratio of $1: 3$ shows about $160 \mathrm{~m}^{2} \mathrm{~cm}^{-3}$. The decrease in surface area originates from the effect that additional larger mesopores are introduced at the expense of smaller ones.

In conclusion, hyperbranched CMS polymers act as unimolecular template species and enable in combination with PEOPB-PEO polymers a simple one-pot synthesis of metal oxides with hierarchically organized bimodal mesoporosity. Both desired pore sizes can be controlled individually by the size of each respective template.

\section{Mesoporous $\mathrm{PdNP} / \mathrm{TiO}_{2}$ catalysts}

CMS-type polymers have been reported to stabilize Pd nanoparticles in colloidal solutions. ${ }^{30}$ We exploited this ability for the synthesis of a $\mathrm{PdNP} / \mathrm{TiO}_{2}$ catalysts from a solution containing preformed colloidal PdNP, CMS10 and the $\mathrm{TiCl}_{4}$ precursor. Deposited films were calcined $\left(450{ }^{\circ} \mathrm{C}\right.$, air) and subsequently reduced $\left(350^{\circ} \mathrm{C}, \mathrm{H}_{2} / \mathrm{Ar}\right)$. Fig. 4 shows SEM and TEM images for the resulting $\mathrm{PdNP} / \mathrm{TiO}_{2}$ catalyst. The top-view SEM image (Fig. 4A) strongly resembles that of the $\mathrm{CMS} 10 / \mathrm{TiO}_{2}$ film without PdNP (Fig. 1D), indicating that the presence of the Pd colloid did not change the CMS10-templated pore geometry. The cross-section SEM image (Fig. 4B) reveals a film thickness of $80 \mathrm{~nm}$. A bright-field TEM image (Fig. 4C) and the corresponding $Z$-contrast TEM image in high-angle annular darkfield mode (HAADF) (Fig. 4D) of the identical part of the catalyst reveal that the preformed colloidal PdNP (BF: black spots, HAADF: bright spots) are well distributed in a mesoporous structure (BF and HAADF: grey area). High-resolution TEM images (Fig. 4E and F) confirm the presence of crystalline $\mathrm{TiO}_{2}$ anatase and Pd. (101)-planes of anatase $(d=0.352 \mathrm{~nm})$ (PDF 211272) can be clearly distinguished in the pore walls (Fig. 4E). Fig. 4F presents a typical Pd particle showing lattice fringes corresponding to metallic Pd, i.e. (111)-planes with $d$-spacing of $0.225 \mathrm{~nm}$, and (200)-planes with $d$-spacing of $0.195 \mathrm{~nm}$ (PDF 461043). The detected PdNPs possess nearly spherical shape. The average PdNP size amounts to $5.6 \pm 1.5 \mathrm{~nm}$ (Fig. $4 \mathrm{H}$ ). SAED (Fig. 4G) shows ring positions that are consistent with anatase (PDF 21-1272).

XRD analysis (Fig. 4I) reveals broad reflections at 2 Theta angles of $25^{\circ}, 36-39^{\circ}$ and $47^{\circ}$ that can be assigned to crystalline $\mathrm{TiO}_{2}$ anatase (PDF 21-1272). At 2 theta of $40^{\circ}$ another weak reflection is observed. The reflection can be assigned to a metallic Pd phase (PDF 46-1043). Other phases, e.g. PdO (PDF 46-1211), were not detected. The average crystallite size (derived from Rietveld refinement) amounted to $11.8 \mathrm{~nm}$ for anatase and $5.3 \mathrm{~nm}$ for Pd. The values are consistent with crystallite and particle sizes extracted from TEM. Compositional analysis of the $\mathrm{PdNP} / \mathrm{TiO}_{2}$ catalyst with ICP-OES indicates a content ratio of $\mathrm{Pd}$ to $\mathrm{TiO}_{2}$ of approximately $2.4 \mathrm{wt} \%$. This value matches closely with the $2.5 \mathrm{wt} \% \mathrm{Pd}$ expected from the composition of the dipcoating solution.

Activity and selectivity of the $\mathrm{PdNP} / \mathrm{TiO}_{2}$ catalyst in the gas phase hydrogenation of 1,3-butadiene are illustrated in Fig. 5 showing (A) the influence of temperature on 1,3-butadiene conversion and (B) selectivity to 1-butene and to selectivity to all butenes (sum of $S_{1 \text {-butene }}, S_{\text {trans-2-butene }}$ and $S_{\text {cis-2-butene }}$ ) vs. butadiene conversion. Both graphs contain corresponding benchmark data for a previously synthesized $0.5 \mathrm{wt} \% \quad \mathrm{PdNP} / \mathrm{TiO}_{2}$ catalyst with a similar PdNP size as reported in ref. 4 . The benchmark catalyst was synthesized with F127 as mesopore template, titanium(Iv) bis(ammonium lactato)dihydroxide (TALH) as $\mathrm{TiO}_{2}$ precursor and colloidal PdNP. ${ }^{4}$ Note that a loading of size-controlled PdNP higher than $0.5 \mathrm{wt} \%$ could not be obtained in this previous study due to the fact that the particle stabilizer (PVP) degraded the micelle-templated pore structure. 

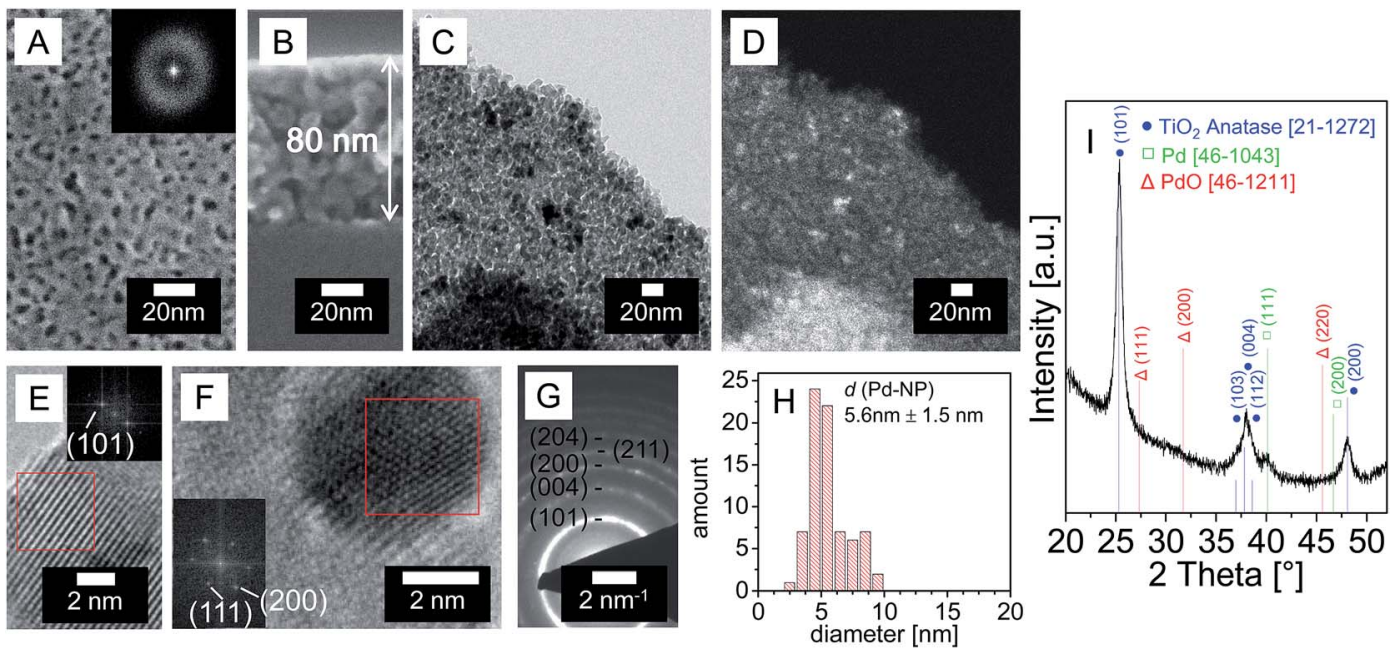

Fig. $4 \mathrm{SEM}$, TEM and XRD analyses of a PdNP/TiO 2 catalyst film calcined at $450{ }^{\circ} \mathrm{C}$ and reduced in $\mathrm{H}_{2} / \mathrm{Ar}$ at $350{ }^{\circ} \mathrm{C}$. Top-view SEM image with FFT inset (A). Cross-section SEM image (B). TEM image in bright-field (C) and high-angle annular dark-field mode (D). HR-TEM images of TiO 2 (E) and

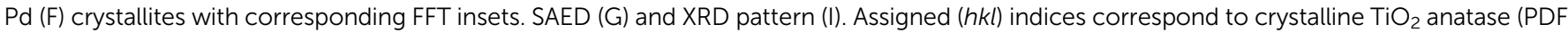
21-1272) and cubic Pd metal (PDF 46-1043), respectively. A histogram of PdNP diameters from TEM analysis is given (H).

A

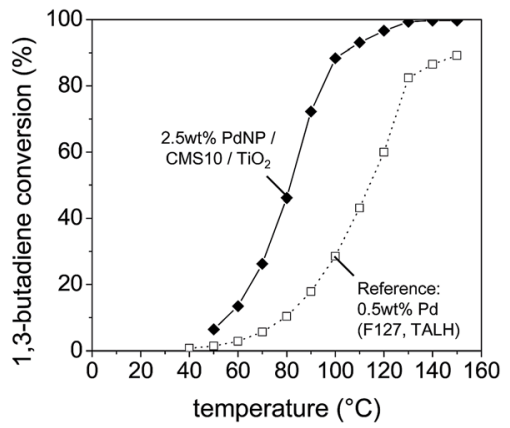

B

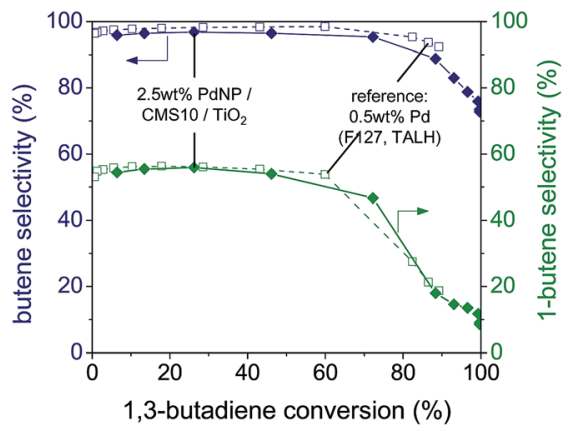

Fig. 5 Catalytic performance of mesoporous $\mathrm{PdNP} / \mathrm{TiO}_{2}$ catalytic coatings. (A) Butadiene conversion vs. temperature. (B) Selectivity to 1-butene and total butane selectivity vs. butadiene conversion. The CMS10-templated catalyst with 2.5 wt\% Pd loading (circles) is compared to a previously reported mesoporous F127-templated $\mathrm{TiO}_{2}$ catalyst film with 0.5 wt\% Pd based on TALH (squares). [4] The five times higher PdNP loading enabled by CMS-templating results in five times higher catalytic activity while the catalyst selectivity remains unaffected.

Both catalysts are active and selective. Butadiene conversion increases with increasing temperature for both catalysts (Fig. 5A). The butadiene conversion at $70{ }^{\circ} \mathrm{C}$ amounted to $26 \%$ for $\mathrm{PdNP} / \mathrm{CMS} 10 / \mathrm{TiCl}_{4}$ and to $5.6 \%$ for $\mathrm{PdNP} / \mathrm{F} 127 / \mathrm{TALH}$, respectively. Thus, the CMS10-templated catalyst shows a $c a$. five times higher activity than the TALH-based reference catalyst. This five times higher activity correlates well with the five times higher Pd loading (2.5 wt\%) that could be achieved only with the new CMS-based catalyst.

Almost identical product selectivities to 1-butene, trans-2butene, cis-2-butene and small amounts of $n$-butane were observed for both catalysts (Fig. 5B). At butadiene conversions up to about $50 \%$ the selectivity for 1 -butene is $55 \%$ which is in line with values reported in literature for other Pd-based catalysts. $^{22}$ Moreover, the Arrhenius plots constructed for both catalysts in the interval 50 to $80{ }^{\circ} \mathrm{C}$ were fitted by straight lines and yielded the same activation energy for both catalyst of about $62 \mathrm{~kJ} \mathrm{~mol}^{-1}$. The equivalent trends in selectivity and activation energy indicate that both catalysts possess the same intrinsic behavior.

Generally, variations of the pore system (pore size, bimodal porosity) can be used to influence the catalytic performance in cases when pore diffusion is limiting. For very small pores the reactant transport in the pore system of the catalyst can be limited by Knudsen diffusion. However, all data presented here were recorded in the kinetic regime. Hence, the data characterize the materials intrinsic catalytic properties, not the effects of pore diffusion.

The space time yield (STY) calculated at $50{ }^{\circ} \mathrm{C}$ for the new mesoporous $\mathrm{PdNP} / \mathrm{CMS} 10 / \mathrm{TiO}_{2}$ catalyst corresponds to $0.122 \mathrm{~mol} \mathrm{~s}^{-1} \mathrm{~kg}^{-1}$. Hence, the developed catalytic coating shows in the kinetic regime and under comparable conditions spacetime-yields for butenes that are at least two to six times higher than values reported in literature (e.g. $0.016 \mathrm{~mol} \mathrm{~s}^{-1} \mathrm{~kg}^{-1},{ }^{31}$ $0.019 \mathrm{~mol} \mathrm{~s}^{-1} \mathrm{~kg}^{-1},{ }^{4} 0.061 \mathrm{~mol} \mathrm{~s}^{-1} \mathrm{~kg}^{-1}$ (ref. 32)). 


\section{Conclusion}

The developed synthesis strategy based on pore templating with core-multishell polymers allows unprecedented control and flexibility in the synthesis of oxide coatings and supported catalysts with small mesopores and with hierarchical porosity. The pore size can be controlled by the size of the template between $3 \mathrm{~nm}$ (CMS5) and 4 to $5 \mathrm{~nm}$ (CMS10), i.e. in a pore size range that is difficult to access with polymer-micelle templates. Due to the templates preformed covalent structure the pore wall thickness was easily adjusted by the ratio between CMS polymer and precursor in the dip-coating solution while keeping the pore size constant. Metal oxide films with hierarchical bimodal porosity prepared by dual soft-templating with CMS polymers and micelle-based templates are accessible for the first time.

Extending the synthesis approach to use CMS polymers as bifunctional NP stabilizer and porogen produces $\mathrm{PdNP} / \mathrm{TiO}_{2}$ catalytic coatings with controlled mesoporosity, a high accessible surface area and high Pd loading. No detrimental effects of the synthesis on the properties of the catalyst support (film integrity, pore templating, pore ordering) or the active PdNP (particle size, activity and selectivity in butadiene hydrogenation) were observed.

Catalytic activity and pore diffusion within the support can be easily tuned with the presented approach. The concept thus provides a versatile and general platform for the rational optimization of catalysts based e.g. on computational prediction of optimal pore structures. ${ }^{33}$ The synthesis also paves the way to model-type catalysts with well-defined pore structure, particle size and high metal loading for the investigation of structureactivity relationships as well as practical applications.

\section{Acknowledgements}

The authors acknowledge Arno Bergmann, Maria Wuithschick, Ulla Vanio and ZELMI at Technical University Berlin for support in material analytics. RK thanks in particular Einstein Foundation Berlin for generous support provided by an EinsteinJunior-Fellowship (EJF-2011-95). DB, EO and RK acknowledge also funding from BMBF (FKZ 03EK3009). JP acknowledges generous funding by the Deutsche Forschungsgemeinschaft within Project PO 1744/1-1. Portions of this research were conducted on beamline B1 at light sources DORIS III and PETRA III at DESY, a member of the Helmholtz Association (HGF).

\section{Literature}

1 J. H. Noh, H. S. Han, S. Lee, J. Y. Kim, K. S. Hong, G. S. Han, H. Shin and H. S. Jung, Adv. Energy Mater., 2011, 1, 829.

2 P. Tiwana, P. Docampo, M. B. Johnston, H. J. Snaith and L. M. Herz, ACS Nano, 2011, 5, 5158.

3 E. V. Rebrov, A. Berenguer-Murcia, H. E. Skelton, B. F. G. Johnson, A. E. H. Wheatley and J. C. Schouten, $L a b$ Chip, 2009, 9, 503.

4 E. Ortel, S. Sokolov, C. Zielke, I. Lauermann, S. Selve, K. Weh, B. Paul, J. Polte and R. Kraehnert, Chem. Mater., 2012, 24, 3828.
5 A. A. Ismail and D. W. Bahnemann, J. Mater. Chem., 2011, 21, 11686.

6 I. L. Violi, M. D. Perez, M. C. Fuertes and G. Soler-Illia, ACA Appl. Mater. Interfaces, 2012, 4, 4320.

7 J. H. Pan, X. S. Zhao and W. I. Lee, Chem. Eng. J., 2011, 170, 363.

8 D. Gu and F. Schüth, Chem. Soc. Rev., 2014, 43, 313.

9 C. Sanchez, C. Boissière, D. Grosso, C. Laberty and L. Nicole, Chem. Mater., 2008, 20, 682.

10 F. Schüth, Angew. Chem., Int. Ed., 2003, 42, 3604.

11 C. J. Brinker, Y. F. Lu, A. Sellinger and H. Y. Fan, Adv. Mater., 1999, 11, 579.

12 B. Smarsly and M. Antonietti, Eur. J. Inorg. Chem., 2006, 1111. 13 V. Novak, P. Koci, F. Stepanek and M. Marek, Ind. Eng. Chem. Res., 2011, 50, 12904.

14 P. C. A. Alberius, K. L. Frindell, R. C. Hayward, E. J. Kramer, G. D. Stucky and B. F. Chmelka, Chem. Mater., 2002, 14, 3284.

15 E. Ortel, A. Fischer, L. Chuenchom, J. Polte, F. Emmerling, B. Smarsly and R. Kraehnert, Small, 2012, 8, 298.

16 K.-S. Jang, M.-G. Song, S.-H. Cho and J.-D. Kim, Chem. Commun., 2004, 1514.

17 M. Yin, Y. Cheng, M. Liu, J. S. Gutmann and K. Müllen, Angew. Chem., Int. Ed., 2008, 47, 8400.

18 S. Nowag, X.-S. Wang, J. Keilitz, A. Thomas and R. Haag, ChemCatChem, 2010, 2, 807.

19 J. Keilitz, M. R. Radowski, J.-D. Marty, R. Haag, F. Gauffre and C. Mingotaud, Chem. Mater., 2008, 20, 2423.

20 S. Sokolov, E. Ortel, J. Radnik and R. Kraehnert, Thin Solid Films, 2009, 518, 27.

21 J. Keilitz, M. Schwarze, S. Nowag, R. Schomäcker and R. Haag, ChemCatChem, 2010, 2, 863.

22 T. Cukic, R. Kraehnert, M. Holena, D. Herein, D. Linke and U. Dingerdissen, Applied Catalysis A-General, 2007, 323, 25.

23 W. Ruland and B. M. Smarsly, J. Appl. Crystallogr., 2007, 40, 409.

24 E. L. Crepaldi, G. Soler-Illia, D. Grosso, F. Cagnol, F. Ribot and C. Sanchez, J. Am. Chem. Soc., 2003, 125, 9770.

25 G. J. A. A. Soler-Illia, P. C. Angelome, M. C. Fuertes, D. Grosso and C. Boissiere, Nanoscale, 2012, 4, 2549.

26 S. Y. Choi, M. Mamak, S. Speakman, N. Chopra and G. A. Ozin, Small, 2005, 1, 226.

27 D. Grosso, G. J. D. A. Soler-Illia, E. L. Crepaldi, F. Cagnol, C. Sinturel, A. Bourgeois, A. Brunet-Bruneau, H. Amenitsch, P. A. Albouy and C. Sanchez, Chem. Mater., 2003, 15, 4562.

28 J. C. Yu, X. C. Wang and X. Z. Fu, Chem. Mater., 2004, 16, 1523. 29 P. Innocenzi, L. Malfatti, T. Kidchob, P. Falcaro, S. Costacurta, M. Guglielmi, G. Mattei, V. Bello and H. Amenitsch, J. Synchrotron Radiat., 2005, 12, 734.

30 M. Schwarze, J. Keilitz, S. Nowag, R. Y. Parapat, R. Haag and R. Schomaecker, Langmuir, 2011, 27, 6511.

31 K. Pattamakomsan, E. Ehret, F. Morfin, P. Gélin, Y. Jugnet, S. Prakash, J. C. Bertolini, J. Panpranot and F. J. C. S. Aires, Catal. Today, 2011, 164, 28.

32 D. C. Lee, J. H. Kim, W. J. Kim, J. H. Kang and S. H. Moon, Appl. Catal., A, 2003, 244, 83.

33 V. Novák, E. Ortel, B. Winter, B. Butz, B. Paul, P. Kočí, M. Marek, E. Spiecker and R. Kraehnert, Chem. Eng. J., 2014, 248, 49. 